\title{
OS CRITÉRIOS JURISDICIONAIS PARA EXONERAÇÃO DA OBRIGAÇÃO DOS PAIS DE PRESTAR ALIMENTOS AOS SEUS FILHOS CIVILMENTE CAPAZES
}

\author{
Tharin Lapolli Fiorenzano da Silveira'
}

Resumo: O presente trabalho trata dos critérios jurisdicionais utilizados para se decidir sobre a exoneração ou a manutenção da prestação de alimentos pelos pais aos seus filhos, quando estes são civilmente capazes.

Para tanto, inicialmente apresentam-se os pressupostos da obrigação de prestar alimentos e do direito a recebê-los, encontrados na doutrina, de modo a possibilitar a compreensão de entendimentos jurisdicionais que, para proceder à exoneração em foco, usam critérios pré-determinados que podem prejudicar o devido julgamento do caso concreto.

Dessa forma, ao final haverá subsídios suficientes a permitir uma contraposição a esses critérios, por meio da legislação pertinente e de argumentos doutrinários.

Considerando o tema apresentado, tratado pelo método de abordagem dedutivo, e as questões por ele envolvidas, no decorrer do trabalho, percebese que a idade de vinte e quatro anos, a conclusão de curso de nível superior, e o fato de o filho não estudar em período integral ou não ser incapaz por

1 Graduada em Direito pela Faculdade de Ciências Sociais de Florianópolis - CESUSC. Cursando especialização em Direito Público pela Escola da Magistratura do Estado de Santa Catarina - ESMESC e pela Universidade Regional de Blumenau - FURB. Assessora Jurídica no Tribunal de Justiça de Santa Catarina. E-mail: tharinlfs@yahoo.com.br 
alguma razão, como doença, são circunstâncias que não podem, por si sós, determinar a exoneração de alimentos por genitores, pois há situações em que, mesmo com a ocorrência dos critérios elencados, subsistirá a necessidade do alimentando e a possibilidade do alimentante.

Palavras-chave: Pais e filhos. Filhos civilmente capazes. Entendimentos Jurisdicionais. Exoneração de alimentos.

\section{INTRODUÇÃo}

Este artigo tem como tema a exoneração da pensão alimentícia, e está delimitado no sentido de verificar os critérios jurisdicionais utilizados para a ocorrência da exoneração da obrigação dos pais de prestar alimentos aos seus filhos civilmente capazes, para averiguar se tais critérios permitem a devida observância das peculiaridades de cada caso concreto.

Após a apresentação dos fundamentos dos magistrados e doutrinadores para a utilização de critérios pré-determinados nas decisões judiciais sobre a exoneração de pensão alimentícia em questão, será possível discorrer sobre os entendimentos contrários.

Por ser um tema atual e muito presente no quotidiano, é clara a viabilidade de perquirir sobre ele, utilizando-se das fontes do direito, como a legislação, a jurisprudência e a doutrina, como a obra de Yussef Said Cahali e de Carlos Roberto Gonçalves, além de artigos.

Quanto à jurisprudência, ter-se-á como base, especialmente, o posicionamento predominante nos Tribunais de Justiça de Santa Catarina e do Rio Grande do Sul, e, ainda, o entendimento do Superior Tribunal de Justiça (STJ), ao se verificar sua Súmula 358.

O método de abordagem a ser utilizado é o dedutivo, pois, por meio do estudo de entendimentos jurisdicionais e identificação de sua fundamentação, se buscará contrapô-los a posicio- 
namentos contrários, no intuito de observar como repercutirão no caso concreto.

O método de procedimento será o monográfico, jurídico, sociológico e hermenêutico, e a técnica de pesquisa será a prescritiva, teórica com base em bibliografia.

O trabalho será estruturado de modo a, inicialmente, apresentar-se os requisitos necessários para prestar, bem como para receber pensão alimentícia.

Após, serão demonstradas as correntes favoráveis à exoneração dos pais de prestar alimentos aos seus filhos com base em critérios utilizados genericamente, seus fundamentos, e como buscam se adequar ao texto da Súmula 358 do Superior Tribunal de Justiça.

Ao final, discorrer-se-á sobre entendimento diverso, atinente com a manutenção dos alimentos após os limites jurisdicionais demonstrados, apresentando-se aspectos importantes a serem analisados, verificando a fundamentação desse entendimento, tratando da Súmula 358 do STJ, e a adequação desta ao posicionamento em questão.

\section{REQUISITOS OU PRESSUPOSTOS PARA PRESTAR E RECEBER ALIMENTOS}

São pressupostos objetivos, de acordo com Carlos Roberto Gonçalves (2006, p. 469), o vínculo de parentesco, o poder familiar, o casamento ou união estável, a necessidade do reclamante e a possibilidade do reclamado, analisados proporcionalmente entre si.

O dever familiar, que gera o dever de sustento, conforme Gonçalves (2006, p. 447), está presente entre os pais e filhos menores, em razão do poder familiar, e entre os cônjuges e companheiros, em razão do dever de mútua assistência.

No entanto, conforme Cahali (2006, p. 454 - 455), além do dever de sustento, há a obrigação alimentar, que perdura mesmo após o fim do poder familiar, pois decorre do paren- 
tesco, com fundamento nos artigos $1.694^{2}$ e $1.696^{3}$ do Código Civil (CC).

Quando os alimentos decorrem do dever de mútua assistência (cônjuge e companheiro) e da obrigação alimentar (vínculo de parentesco), para que persistam deve haver necessidade de quem os busca, e possibilidade do alimentante de prestá-los (GONÇALVES, 2006, p. 473 - 474), conforme preconiza o artigo $1.695^{4}$, CC.

Por fim, conforme o pressuposto da proporcionalidade, a necessidade e possibilidade devem ser analisadas conjuntamente, para verificação da existência de obrigação e direito a alimentos, e aferição do seu quantum (GONÇALVES, 2006, p. 470).

Quanto aos pressupostos subjetivos, o dever de sustento, por decorrer do poder familiar, é devido pelos pais aos seus filhos menores de dezoito anos, mas estes não os devem àqueles (CAHALI, 2006, p. 454). O artigo 1.5665 , CC, trata do assunto. Já na obrigação alimentar, de acordo com Silvio Rodrigues (2004, p. 380 - 381), há reciprocidade, por decorrer do parentesco (linha reta, colateral até o segundo grau, conforme o artigo $1.697^{6}, \mathrm{CC}$, e os parentes por afinidade).

2 Art. 1.694. Podem os parentes, os cônjuges ou companheiros pedir uns aos outros os alimentos de que necessitem para viver de modo compatível com a sua condição social, inclusive para atender às necessidades de sua educação.

$\S 1$ o Os alimentos devem ser fixados na proporção das necessidades do reclamante e dos recursos da pessoa obrigada.

$\S 20$ Os alimentos serão apenas os indispensáveis à subsistência, quando a situação de necessidade resultar de culpa de quem os pleiteia.

3 Art. 1.696. O direito à prestação de alimentos é recíproco entre pais e filhos, e extensivo a todos os ascendentes, recaindo a obrigação nos mais próximos em grau, uns em falta de outros.

4 Art. 1.695. São devidos os alimentos quando quem os pretende não tem bens suficientes, nem pode prover, pelo seu trabalho, à própria mantença, e aquele, de quem se reclamam, pode fornecê-los, sem desfalque do necessário ao seu sustento.

5 Art. 1.566. São deveres de ambos os cônjuges:

[...]

IV - sustento, guarda e educação dos filhos;

6 Art. 1.697. Na falta dos ascendentes cabe a obrigação aos descendentes, guardada a ordem de sucessão e, faltando estes, aos irmãos, assim germanos como unilaterais. 
Tratando dos alimentos em razão do parentesco, Gonçalves (2006, p. 480 - 481) afirma que, antes de se cobrar alimentos de um parente, deve-se cobrar do cônjuge ou companheiro, e só então segue-se a ordem preferencial inserta nos artigos 1.696 e 1.697, ambos do Código Civil: "[...] a) pais e filhos, reciprocamente; b) na falta destes, os ascendentes, na ordem de sua proximidade; c) os descendentes, na ordem de sucessão; d) os irmãos, unilaterais ou bilaterais, sem distinção ou preferência".

\section{CRITÉRIOS PRÉ-DETERMINADOS DE EXONERAÇÃO DE ALIMENTOS E SEUS FUNDAMENTOS}

Explica-se, na jurisprudência, que a exoneração de alimentos decorre, em princípio, da maioridade civil atingida pelos filhos ${ }^{7}$, pois, nesse momento, acaba o poder familiar, cessa o dever de sustento e educação ${ }^{8}$, conforme se depreende da leitura conjunta dos artigos $5^{\circ 9}, 1.635, \mathrm{III}^{10}$ e $1.634, \mathrm{I}^{11}$ do CC e artigo $22^{12}$ do Estatuto da Criança e do Adolescente (ECA), e da doutrina de Cahali (2006, p. 454).

7 TJSC, Ap. Cív. n. 2008.040304-2, de Araquari, rel. Des. Edson Ubaldo, j. em 8-12009; TJSC, Ap. Cív. n. 2008.006428-0, de Tubarão, rel. Des. Sérgio Izidoro Heil, j. em 8-1-2009; TJSC, Ap. Cív. n. 2008.037090-1, de Camboriú, rel. Des. Trindade dos Santos, j. em 25-11-2008; TJSC, Ap. Cív. n. 2008.007203-6, de Tubarão, rel. Des. Marcus Tulio Sartorato, j. em 29-9-2008.

8 TJSC, Ap. Cív. n. 2008.006428-0, de Tubarão, rel. Des. Sérgio Izidoro Heil, j. em 8-1-2009; TJSC, Ap. Cív. n. 2008.037090-1, de Camboriú, rel. Des. Trindade dos Santos, j. em 25-11-2008; TJSC, Ap. C. n. 2008.007203-6, de Tubarão, rel. Des. Marcus Tulio Sartorato, j. em 29-9-2008.

9 Art. 1.635. Extingue-se o poder familiar:

[...]

III - pela maioridade;

10 Art. 1.634. Compete aos pais, quanto à pessoa dos filhos menores:

I - dirigir-lhes a criação e educação;

11 Art. 22. Aos pais incumbe o dever de sustento, guarda e educação dos filhos menores, cabendo-lhes ainda, no interesse destes, a obrigação de cumprir e fazer cumprir as determinações judiciais.

12 TJSC, Al. n. 2008.032607-0, de São João Batista, rel. Des. Trindade dos Santos, j. em 25-11-2008; TJSC, Ap. Cív. n. 2004.001869-0, de São Bento do Sul, rel. Des. Luiz Carlos Freyesleben, j. 13-5-2004; TJSC, Al. n. 2007.021193-4, da Capital, rel. Des. Carlos Prudêncio, j. em 25-7-2008; TJSC, Ap. C. n. 2008.040304-2, de Araquari, rel. Des. Edson Ubaldo, j. em 8-1-2009; TJSC, AI. n. 2008.0215519, de Chapecó, rel. Des. Henry Petry Junior, j. em 19-12-2008; TJSC, Al. n. 2006.028072-3, de Blumenau, rel. Des. Carlos Prudêncio, j. em 3-9-2008. 
Há magistrados que, quando decidem que o filho continuará a receber pensão alimentícia após a aquisição da maioridade civil, explicam que se trata de prorrogação do dever de sustento, que pode ocorrer, conforme fundamentam, em razão de que os alimentos também se destinam à complementação de estudos superiores dos filhos, sendo que é escolhida a idade de 24 anos como limite a essa prorrogação, porque consideram que se trata de idade razoável para a conclusão dos estudos em questão ${ }^{13}$.

Cahali (2006, p. 467) também entende desse modo, pois o dever de sustento e o dever alimentar decorrente do parentesco possuem diferenças suficientes, como quanto aos seus pressupostos, para impossibilitar que um simplesmente se transforme no outro.

Explica Cahali (2006, p. 467), ainda, que essa transformação geraria a "[...] inovação de uma relação jurídica, ocorrida no âmbito de um processo [...]" levando-se em conta "[...] aqueles casos em que o filho não foi parte no processo (separação judicial ou divórcio)".

Há magistrados que fundamentam essa possibilidade de prolongamento na dignidade humana e no dever de solidariedade familiar, afirmando que só é possível quando o filho é responsável ${ }^{14}$.

Ênio Santarelli Zuliani (2007, p. 55) concorda, e acrescenta que a solidariedade familiar é ininterrupta e adequa-se

13 TJSC, Al. n. 2008.021551-9, de Chapecó, rel. Des. Henry Petry Junior, j. em 1912-2008.

14 TJSC, Ap. Cív. n. 2008.011146-2, de Tubarão, rela. Desa. Maria do Rocio Luz Santa Ritta, j. em 2-10-2008; TJSC, Al. n. 2007.021193-4, da Capital, rel. Des. Carlos Prudêncio, j. em 25-7-2008; TJSC, Ap. Cív. n. 2008.005655-1, de Tijucas, rela. Desa. Maria do Rocio Luz Santa Ritta, j. em 2-10-2008; TJSC, Al. n. 2006.028072-3, de Blumenau, rel. Des. Carlos Prudêncio, j. em 3-9-2008; TJSC, Ap. Cív. n. 2008.006428-0, de Tubarão, rel. Des. Sérgio Izidoro Heil, j. em 8-12009; TJSC, Ap. Cív. n. 2006.022431-6, de Palmitos, rel. Des. Sérgio Izidoro Heil, j.em 28-11-2008; TJSC, Al. n. 2005.032402-2, da Capital, rel. Des. Monteiro Rocha, j. em 31-7-2008; TJPR, Ap. Cív. n. 10791, de Santa Izabel do Ivaí, rel. Des. Augusto Côrtes, j. em 30-7-2008; TJSC, Al. n. 2008.048797-6, de Videira, rel. Des. Marcus Túlio Sartorato, j. em 3-11-2008; TJSC, Ap. Cív. n. 2008.037090-1, de Camboriú, rel. Des. Trindade dos Santos, j. em 25-11-2008. 
ao princípio da dignidade da pessoa humana e ao artigo 229 da Constituição da República Federativa do Brasil (CRFB), onde se lê que "os pais têm o dever de assistir, criar e educar os filhos menores, e os filhos maiores têm o dever de ajudar e amparar os pais na velhice, carência ou enfermidade".

Conceituando o princípio da dignidade da pessoa humana, Rodrigo da Cunha Pereira (2006, p. 98) afirma que se trata da "[...] certeza de que determinados direitos devem ser atribuídos às pessoas por uma mesma causa universal e acima de qualquer arbítrio humano [...]", relacionado às "[...] necessidades humanas determinadas pela sua natureza, e que nenhum Estado tem o poder de modificar [...]".

Por outro lado, alguns magistrados explicam que a possibilidade de o filho receber alimentos após a maioridade, se estiver estudando, está relacionada à obrigação de alimentar decorrente da relação de parentesco (artigo 1.694, CC), e não ao dever de sustento, pois este termina com a maioridade civil do alimentando (artigos 1.634, inciso I, 1.635, III, e 1.566, IV, CC, artigo 229, primeira parte, CRFB).

Afirma, ainda, que esses os alimentos podem perdurar até os 24 anos do alimentando, se estiver estudando, para sua inserção no mercado de trabalho ${ }^{15}$.

Por meio dos dispositivos legais citados, os magistrados visam demonstrar que o poder familiar, e conseqüente o dever de sustento, terminam quando começa a maioridade. Quanto ao artigo 229, CRFB, pretendem salientar sua primeira parte, onde está escrito que "os pais têm o dever de assistir, criar e educar os filhos menores [...]”. No mesmo sentido, é o entendimento de Sílvio de Salvo Venosa (2007, p. 351).

Alguns magistrados entendem que se os filhos têm tempo de trabalhar, mesmo sendo estudantes menores de 24 anos de idade, deve ocorrer a exoneração, como no caso dos filhos

15 TJSC, Ap. Cív. n. 2008.011146-2, de Tubarão, rela. Desa. Maria do Rocio Luz Santa Ritta, j. em 2-10-2008. 
que estudam à noite, pois consideram que poderiam trabalhar durante o dia ${ }^{16}$.

Um dos fundamentos utilizados para essa limitação ou prorrogação do recebimento de alimentos é a própria jurisprudência. Os magistrados aduzem que, entre os motivos pelos quais a pensão só pode ir até os 24 anos do filho e somente se estiver estudando, é se tratar de entendimento jurisprudencial ${ }^{17}$.

Utiliza-se também a fundamentação doutrinária ${ }^{18}$, como se encontra, por exemplo, na obra de Gonçalves (2006, p. 475), Cahali (2006, p. 467) e Venosa (2007, p. 351).

Alguns juízes entendem que os filhos maiores de dezoito anos, para continuar a receber alimentos, precisam propor ação própria com base na relação de parentesco, e provar elementos relevantes que consideram ser, justamente, a freqüência em curso universitário até os 24 anos, além de doença que impeça de manter-se, e qualquer incapacidade para o trabalho, como o caso de curso que impossibilite horários livres para trabalhar ${ }^{19}$.

Muitos desses magistrados fundamentam esse entendimento na obra de Jorge Luís Costa Beber (1999, p. 168).

Para a posição jurisdicional segundo a qual os alimentos devidos após a maioridade se dão pela prorrogação do dever de sustento, essa continuidade é possível em razão da analogia em

16 TJSC, Ap. Cív. n. 2008.006428-0, de Tubarão, rel. Des. Sérgio Izidoro Heil, j. em 8-1-2009; TJSC, Ap. Cív. n. 2008.011146-2, de Tubarão, rela. Desa. Maria do Rocio Luz Santa Ritta, j. em 2-10-2008; TJSC, Al. n. 2006.028072-3, de Blumenau, rel. Des. Carlos Prudêncio, j. em 3-9-2008; TJSC, AI. n. 2005.032402-2, da Capital, rel. Des. Monteiro Rocha, j. em 31-7-2008.

17 TJSC, Al. n. 2006.028072-3, de Blumenal, rel. Des. Carlos Prudêncio, j. em 3-92008; TJSC, Ap. Cív. n. 2004.000896-1, de Itapianga, rel. Des. Wilson Augusto do Nascimento, j. em 2-4-2004.

18 TJSC, Ap. Cív. n. 2008.011146-2, de Tubarão, rela. Desa. Maria do Rocio Luz Santa Ritta, j. em 2-10-2008; TJSC, Al. n. 2007.021193-4, da Capital, rel. Des. Carlos Prudêncio, j. em 25-7-2008; TJSC, Ap. Cív. n. 2008.005655-1, de Tijucas, rela. Desa. Maria do Rocio Luz Santa Ritta, j. em 2-10-2008.

19 TJSC, Al. n. 2008.021551-9, de Chapecó, rel. Des. Henry Petry Junior, j. em 1912-2008; TJSC, Ap. Cív. n. 2002.003308-1, da Capital, rel. Des. Mazoni Ferreira, j. em 25-4-2002; TJSC, Ap. Cív. n. 2001.008188-1, da Capital, rel. Des. Mazoni Ferreira, j. em 20-8-2001. 
relação à Lei n. 1.474, de 26 de novembro $1.951^{20}$, que, em seu artigo 1, modificou a legislação do Imposto de Renda.

Segundo Cahali (2006, p. 460), o disposto na Lei n. 1.474/1951, informa que aos filhos menores de 18 anos, se equiparam os menores de 24 anos que façam curso em estabelecimento superior, e acrescenta que, "[...] atualmente a matéria é regida pelo artigo 35, III e V, e $\$ 1 .^{\circ}$ da Lei 9.250/95[...]”.

Na mencionada Lei n. 9.250 de 26 de dezembro de 1995, lê-se:

Art. 35. Para efeito do disposto nos arts. 4\%, inciso III, e $8^{\circ}$, inciso II, alínea c, poderão ser considerados como dependentes:

[...]

III - a filha, o filho, a enteada ou o enteado, até 21 anos, ou de qualquer idade quando incapacitado física ou mentalmente para o trabalho;

[...]

V - o irmão, o neto ou o bisneto, sem arrimo dos pais, até 21 anos, desde que o contribuinte detenha a guarda judicial, ou de qualquer idade quando incapacitado física ou mentalmente para o trabalho;

[...]

$\S 1^{\circ}$ Os dependentes a que se referem os incisos III e $\mathrm{V}$ deste artigo poderão ser assim considerados quando maiores até 24 anos de idade, se ainda estiverem cursando estabelecimento de ensino superior ou escola técnica de segundo grau (grifo nosso).

Sobre o exposto, Venosa (2007, p. 351) afirma: "tem-se entendido que, por aplicação do entendimento fiscal quanto à dependência para o Imposto de Renda, que o pensionamento deva ir até os 24 anos de idade”.

20 TJSC, Al. n. 2008.021551-9, de Chapecó, rel. Des. Henry Petry Junior, j. em 1912-2008. 
Os magistrados que são a favor dessa analogia, explicam que inicialmente, os alimentos seriam devidos unicamente até a maioridade, já que não há previsão legal de prorrogação do dever de sustento, mas que, como faz parte desse dever a mais abrangente formação profissional dos filhos, construiu-se a analogia acima referida.

Encontrou-se decisão em que se aduz, inclusive, ser possível essa analogia em razão de que os pais devem oferecer o maior conforto para que seus filhos tenham a melhor formação profissional, ressalvando que os alimentos devem se restringir a essa formação, já que a presunção das necessidades é mais branda com o advento da maioridade, e citando o enunciado 344 da IV Jornada de Direito Civil (CONSELHO DA JUSTIÇA FEDERAL, 2006) ${ }^{21}$, que dispõe: "A obrigação alimentar originada do poder familiar, especialmente para atender às necessidades educacionais, pode não cessar com a maioridade”.

Independente de entender-se que a manutenção da pensão alimentícia para além da maioridade ocorre pela prorrogação do dever de sustento ou pelo fim desse dever seguido do surgimento da obrigação alimentar decorrente da relação de parentesco, as decisões jurisdicionais em foco justificam a utilização dos critérios subjetivos limitadores do pensionamento na presunção de que, a partir da formação em curso de nível superior, o alimentando já tem condições de ingressar no mercado de trabalho, e mesmo que com alguma dificuldade, garantir seu próprio sustento ${ }^{22}$, ressaltando neste sentido, que os alimentos não podem servir de estímulo ao ócio e ao parasitismo ${ }^{23}$.

21 TJSC, Ap. Cív. n. 2005.019482-1, de Balneário Camboriú, rel. Des. Luiz Carlos Freyesleben, j. em 6-5-2008; TJSC, Al. n. 2006.028072-3, de Blumenau, rel. Des. Carlos Prudêncio, j. em 3-9-2008.

22 TJSC, Ap. Cív. n. 2005.019482-1, de Balneário Camboriú, rel. Des. Luiz Carlos Freyesleben, j. em 6-5-2008; TJSC, Ap. Cív. n. 2008.007203-6, de Tubarão, rel. Des. Marcus Tulio Sartorato, j. em 29-9-2008.

23 TJSC, Ap. Cív. n. 2007.036056-7, de São José, rel. Des. Joel Figueira Júnior, j. em 26-5-2008; TJSC, Al. n. 2008.048797-6, de Videira, rel. Des. Marcus Túlio Sartorato, j. em 3-11-2008; TJSC, Ap. Cív. n. 2008.037090-1, de Camboriú, rel. Des. Trindade dos Santos, j. em 25-11-2008; TJSC, Ap. Cív. n. 2008.007203-6, de Tubarão, rel. Des. Marcus Tulio Sartorato, j. em 29-9-2008. 
Gonçalves (2006, p. 475), referindo-se ao ócio, aduz que o direito aos alimentos deve cessar quando o alimentando é irresponsável nos estudos, e quando sempre se matricula em cursos superiores, para, na verdade, continuar recebendo os alimentos.

Alguns magistrados dizem que a continuidade do pensionamento em análise é possível quando os alimentandos têm doenças que reduzem ou impedem a capacidade laboral, ou pelo fato de estarem estudando, pois, com a extinção do poder familiar inverte-se o ônus da prova acerca da necessidade de percepção dos alimentos ${ }^{24}$. Afirmam que se trata de pensamento admitido pela jurisprudência e doutrina, o que, de fato, se verifica na obra de Silvio Rodrigues (2004, p. 386) e de Carlos Roberto Gonçalves (2006, p. 474).

Salienta-se, por fim, que há magistrados que prorrogam excepcionalmente o limite referente à idade de 24 anos, para que o filho possa concluir seus estudos, caso em que ressaltam que a exoneração deve ocorrer na data da colação de grau ${ }^{25}$.

\subsection{Súmula 358 do Superior Tribunal de Justiça e entendimentos sobre a exoneração automática dos alimentos pelo alcance da maioridade}

Há entendimentos jurisdicionais e doutrinários, no sentido de que os critérios em questão devem ser genericamente utilizados. Dentro desse entendimento, discute-se apenas, conforme afirma Cahali (2006, p. 456), forma e o momento dessa exoneração.

24 TJSC, Al. n. 2007.021193-4, da Capital, rel. Des. Carlos Prudêncio, j. em 25-72008; TJSC, Ap. Cív. n. 2005.019482-1, de Balneário Camboriú, rel. Des. Luiz Carlos Freyesleben, j. em 6-5-2008; TJSC, Al. n. 2006.028072-3, de Blumenau, rel. Des. Carlos Prudêncio, j. em 3-9-2008; TJSC, AI. n. 2006.028072-3, de Blumenau, rel. Des. Carlos Prudêncio, j. em 3-9-2008.

25 TJSC, Al. n. 2004.001869-0, de São bento do Sul, rel. Des. Luiz Carlos Freyesleben, j. em 13-5-2004; TJSC, Ap. Cív. n. 2006.032971-9, de Joaçaba, rel. Des. Luiz Carlos Freyesleben, j. em 22-2-2007; TJSC, Al. n. 2007.019526-9, de Joaçaba, rel. Des. Henry Petry Junior, j. em 14-3-2008. 
De acordo com a Súmula 358 do Superior Tribunal de Justiça (BRASIL, 2008), não pode findar o pensionamento sem o contraditório. No entanto, Cahali (2006, p. 456 - 457) entende que a obrigação de prestar alimentos em razão do dever de sustento, por ser este atrelado ao poder familiar, deve cessar automaticamente quando esse poder findar, e acrescenta que, em razão da relação de parentesco que nasceu, cabe ao filho, agora, pelas vias próprias, buscar os alimentos mediante prova de sua necessidade.

Há entendimento (CAHALI, 2006, p. 467 - 468), no entanto, que, mesmo reconhecendo que tal exoneração deve ser automática, abre exceções para situações específicas, como o caso do filho estudante de curso superior com menos de 24 anos de idade, sendo esse argumento utilizado para buscar adequar a possibilidade de exoneração automática à Súmula 358 do Superior Tribunal de Justiça (BRASIL, 2008), que possui o seguinte texto: "o cancelamento de pensão alimentícia do filho que atingiu a maioridade está sujeito à decisão judicial, mediante contraditório, ainda que nos próprios autos".

Beber (1999, p. 169) aduziu que esse tipo de exceção "[...] ocasiona prejuízos pecuniários para a expressiva maioria daqueles pais que já honraram com a sua obrigação alimentar", e argumenta que a exoneração automática impede que o alimentante se aproveite da morosidade do processo judiciário e da possibilidade de recurso, para "[...] continuar recebendo um crédito que sabe indevido".

\section{MANUTENÇÃO DOS ALIMENTOS APÓS OS LIMITES JURISDICIONAIS DE PRESTAÇÃO DE ALIMENTOS DOS PAIS AOS SEUS FILHOS CIVILMENTE CAPAZES}

Inicialmente, é importante discorrer acerca dos prejuízos que as limitações até aqui mencionadas podem ocasionar à vida do filho alimentando.

Expõe Zuliani (2007, p. 64 - 65), diversas situações particulares, relacionadas especialmente às necessidades intelectuais, 
mas, por intermédio delas, demonstra que todas decorrem da análise do caso concreto, e que essa análise cuidadosa é capaz de alterar completamente o resultado de uma decisão judicial, o que se constata especialmente quando o autor afirma: "[...] o que vale, para decidir, é a análise do 'estado de necessidade”.

Zuliani (2007, p. 54) ressalta a importância de o filho, de qualquer idade, ter a oportunidade de estudar, e afirma: "[...] para se viver, é preciso estudar, porque a instrução é a garantia do bem-estar dos homens". Além disso, discorre acerca da dificuldade do crescimento intelectual e profissional do indivíduo que, mesmo querendo e se esforçando, não tem condições financeiras para arcar com seus estudos (ZULIANI, 2007, p. 55).

Arnaldo Rizzardo (2005, p. 756) ressalta que a formação em curso superior não pode ocasionar exoneração de alimentos, tendo em vista a "[...] dificuldade em se conseguir uma colocação na atividade para a qual se preparou o filho”.

Portanto, conforme salienta Zuliani (2007, p. 65), a continuidade dos estudos de que se está a tratar, não é algo supérfluo ou exagerado, mas sim um meio do recém-formado conseguir colocação digna no mercado de trabalho, de modo que, tendo condições financeiras, os pais possuem a obrigação de auxiliar o filho nas despesas decorrentes dos cursos preparatórios.

Essa obrigação dos pais em auxiliar seus filhos na formação profissional, na obtenção de uma vida digna, encontra respaldo nas explicações de Rolf Madaleno (2005, p. 235), segundo o qual, os alimentos servem principalmente para permitir que a pessoa com necessidade de recebê-los possa ter uma subsistência minimamente digna, através dos alimentos que os parentes do necessitado estão obrigados a prestar, uma vez que inseridos em "[...] um contesto de inquestionável solidariedade familiar", com o que concorda Cristiano Chaves de Farias (2004, p. 104 - 105).

Tratando especificamente sobre o enfoque deste trabalho, Farias (2005, p. 40) explica que, mesmo que a maioria da doutrina e da jurisprudência afirme que os alimentos devem cessar aos 24 anos quando o filho é estudante, deve-se atentar 
para as peculiaridades de cada caso e para o atendimento da solidariedade.

Nesse sentido, Zuliani (2007, p. 71) alerta para o fato de que a exoneração de alimentos que ocorre sem atenção devida ao caso concreto pode ocasionar interrupção nos planos de ascensão intelectual que possui o alimentando, gerando um "[...] risco que se elimina agindo com cautela ou sem pressa”, e ainda, conforme Farias (2005, p. 39), tendo em conta que "[...] mais grave do que permitir o recebimento de alimentos sem necessidade é privar alguém de recebê-los quando necessita”.

\subsection{Verificação das funamentações das correntes}

Ao contrário das motivações até agora demonstradas para justificar a aplicação genérica de requisitos pré-fixados para se decidir sobre a exoneraçã de alimentos em questão, Farias (2005, p. 36 - 37) afirma que, como a solidariedade familiar não cessa pela maioridade, esta não é motivo capaz de sozinha, ensejar autorização ao alimentante para que deixe de prestar alimentos, sendo.

Ainda, conforme Farias (2005, p. 39), “[...] a própria Codificação não estabelece prazo para o término da pensão alimentícia [...]”, ou seja, não há nenhum dispositivo legal que limite a prestação de alimentos em razão do alcance de qualquer idade, nem na formação em curso superior, uma vez que a legislação e a doutrina são claras em delimitar quais os requisitos que precisam ser preenchidos para que se possa ter direito a receber alimentos, que são a necessidade do alimentando e a possibilidade do alimentante, conforme Caio Mário da Silva Pereira (2006, p. 497 - 498), Silmara Juny Chinelato (2004, p. 451), Rodrigo da Cunha Pereira (2005, p. 4) e Farias (2005, p. 31).

Os efeitos da diferenciação do dever de sustento e da obrigação alimentar não levam ao entendimento de que os filhos que atingiram a maioridade devem deixar de receber alimentos, 
nem vinculam a prestação de alimentos à condição de estudante de nível superior ou técnico do alimentando, uma vez que esses efeitos indicam apenas que, no primeiro caso, os alimentos são devidos independentemente da ocorrência dos pressupostos da necessidade e possibilidade, enquanto que no segundo caso, o alimentando deve provar esses mesmos pressupostos (GONÇALVES, 2006, p. 473 - 474).

Do mesmo modo, o fato de a incapacidade decorrente de doença servir como presunção da necessidade de alimentos, não significa que o fiho saudável também não tenha necessidade de recebê-los, conforme se depreende de Pereira (2006, p. 497 - 498).

Além do critério de exoneração pela idade de 24 anos e formação em curso superior, há entendimento no sentido de exonerar os pais de prestar alimentos quando a duração diária do curso permite horário livre, que para este entendimento, deve ser usado para trabalhar, sob pena de se estar estimulando o ócio.

No entanto, mais uma vez, alerta-se para a análise do caso concreto, pois, conforme Gonçalves (2006, p. 475), evita-se o estímulo à ociosidade fazendo cessar os alimentos dos alimentandos irresponsáveis em seus estudos, daqueles que sempre estão se matriculando em cursos superiores, no intuito de continuar a receber alimentos, o que não diz respeito, no entendimento de Zuliani (2007, p. 67), aos filhos responsáveis, dedicados, que se utilizam do tempo em que não estão na aula para aperfeiçoar seus estudos.

Quanto aos princípios da solidariedade e da dignidade da pessoa humana, em relação à pensão alimentícia (FARIAS, 2005, p. 27, 32), atuam no sentido de garantir a manutenção das pessoas com vínculo de parentesco entre si, de modo a suprir deficiências que, como o desemprego, impedem "[...] a concretização dos direitos econômicos e sociais afirmados pelo Pacto Social de 1988".

A dignidade da pessoa humana, segundo Edinês Maria Sormani Garcia (2003, p. 45, 129) é direito fundamental 
previsto no artigo $1^{\circ}$, III ${ }^{26}, \mathrm{CRFB}$, tem aplicação no âmbito da família reconhecida constitucionalmente, no artigo $226^{27}$, CRFB, segundo o qual "a família, base da sociedade, tem especial proteção do Estado”, e coaduna-se (FARIAS, 2005, p. 28) com a reciprocidade do dever de prestar alimentos que existe entre os parentes, de acordo com o artigo 1.696, CC.

Segundo Pereira (2005, p. 1 - 2), os alimentos harmonizamse com a dignidade da pessoa humana, na medida em que são destinados à manutenção de quem não pode arcar com o próprio sustento, de modo que (FARIAS, 2005, p. 40), mesmo tendo algum rendimento, o alimentando poderá continuar a receber alimentos se tais rendimentos não forem suficientes para uma vida digna.

O Principio da Solidariedade (PEREIRA, 2005, p. 2, 19) refere-se a direito fundamental com previsão no artigo $3^{\circ}, \mathrm{I}^{28}$, CRFB, que adentrou na esfera da família, "[...] vez que reflete o atual 'espírito' da família contemporânea”.

Ainda, quando o comando constitucional refere a "sociedade solidária" inclui, evidentemente, a "base da sociedade", que é a família (LÔBO, 2007, p. 149, 159), âmbito no qual se percebe a solidariedade no dever da sociedade, do Estado e da própria família, de proteger o grupo familiar, de acordo com o artigo 226, CRFB.

Importante demonstrar que há entendimentos jurisdicionais nos quais se percebe a verificação mais cuidadosa do caso concreto, o que foi encontrado, entre os Tribunais de Justiça pesquisados, especialmente no Tribunal de Justiça do Rio Grande do Sul:

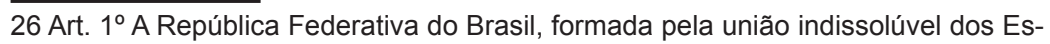
tados e Municípios e do Distrito Federal, constitui-se em Estado Democrático de Direito e tem como fundamentos:

[...]

III - a dignidade da pessoa humana;

27 Art. 226. A família, base da sociedade, tem especial proteção do Estado.

28 Art. $3^{\circ}$ Constituem objetivos fundamentais da República Federativa do Brasil: I - construir uma sociedade livre, justa e solidária; 
APELAÇÃO CÍVEL. AÇÃO DE EXONERAÇÃO E REVISIONAL DE ALIMENTOS. ALTERAÇÃO DO BINÔMIO POSSIBILIDADE/NECESSIDADE. FILHO MAIOR QUE CURSA ENSINO SUPERIOR. MANUTENÇÃO DOS ALIMENTOS POR PRAZO CERTO.

[...]

Embora, o requerido, nascido em 13.09.1983, já tenha implementado a maioridade, pois conta com 25 anos de idade (fl. 73), segundo o que consta dos autos, ele ainda necessita dos alimentos, pois apenas estuda, cursa a faculdade de Direito no IPA, isto é, não trabalha, e reside em imóvel locado, tendo ainda acolhido a irmã de 16 anos de idade, porque a mãe dos mesmos possui problemas com droga (fl. 151).

[...]

E, ainda que esteja fazendo estágio e participe de campeonatos de Taikendo, percebendo alguma renda, o que é positivo, deve-se levar em conta que tais atividades não possuem vínculo empregatício e regularidade.

$[\ldots]$

Assim, comprovadas as necessidades do requerido e as possibilidades do autor, mostra-se correta a decisão que manteve os alimentos anteriormente fixados.

[...] (TJRS, Ap. C. n. 70027347442, de Porto Alegre, Rel. Des. Ricardo Raupp Ruschel, j. em 03-12-2008).

Observa-se que, nessa decisão, os alimentos foram mantidos mesmo após os 24 anos do alimentando, uma vez que, no caso concreto, observou-se sua necessidade.

No mesmo sentido, o seguinte acórdão:

AGRAVO DE INSTRUMENTO. AÇÃO DE EXONERAÇÃO DE ALIMENTOS. LIMINAR 
DE REDUÇÃO NO QUANTUM. DESCABIMENTO.

As alegações do alimentante, de que a alimentada não teria mais necessidades, não têm verossimilhança.

Os alimentos foram fixados quando ela já era maior da idade e estava encerrando curso superior. A recente colação de grau, por si só, não é prova suficiente de que as necessidades desapareceram.

$[\ldots]$

Nesse contexto, e mesmo considerando ser fato certo que a alimentada concluiu o curso superior de Direito e está advogado [sic], não penso ser adequada a redução tão brusca do pensionamento.

[...] (TJRS, AI. n. 70026810689, de Porto Alegre, Rel. Des. Rui Portanova, j. em 08-10-2008).

Demonstrando grande zelo ao analisar o caso concreto, os magistrados que proferiram o acórdão em foco, permitiram a continuidade do pagamento de pensão alimentícia à filha que já possuía 34 anos de idade, pois as peculiaridades do caso específico demonstraram sua necessidade, ao menos em primeira análise, pois se trata de decisão de pedido liminar.

\subsection{Súmula 358 do Superior Tribunal de Justiça e a análise do caso concreto}

Passa-se a demonstrar os entendimentos que se coadunam com a Súmula 358 do Superior Tribunal de Justiça (BRASIL, 2008):

O cancelamento de pensão alimentícia de filho que atingiu a maioridade está sujeito à decisão judicial, mediante contraditório, ainda que nos próprios autos (BRASIL, 2008, grifo nosso).

O Recurso Especial n. 347.010 é um dos seus precedentes, e demonstra o raciocínio que resultou na sua concretização: 
[...] após os debates, a Turma considerou conveniente que o relator procurasse saber qual a prática adotada nas varas de família. [...].

Recolhi a informação de que, nesse caso, de um modo geral, (a) os alimentantes requerem nos autos da ação originária o cancelamento da obrigação ou a proporcional redução; (b) os juízes aceitam esse procedimento e determinam a intimação dos interessados; (c) se houver a concordância, o requerimento é deferido; (d) caso contrário, se o alimentando alegar que ainda necessita da prestação, duas são as alternativas adotadas com mais freqüência, (d-1) ou o devedor é encaminhado à ação de revisão/cancelamento, (d-2) ou é instaurado nos mesmos autos uma espécie de contraditório, ao cabo do qual o juiz decide pelo cancelamento ou pela manutenção.

[...] Verifico que, realmente, o fato da maioridade é causa extintiva ipso jure do dever que decorre do pátrio poder, por isso não é razoável se imponha ao alimentante a iniciativa de uma ação de exoneração, com todos os inconvenientes que disso decorrem. De outro lado, é também muito comum que o filho, ao atingir a maioridade, ainda necessite da contribuição paterna [...]. Tal seja o caso, não seria razoável o automático cancelamento da prestação, a exigir do filho ingressar com ação de alimentos para manter a prestação alimentar, uma vez que se trata de simples continuidade da situação existente.

[...] (STJ, REsp. n. 347.010, de São Paulo, Rel. Min. Ruy Rosado de Aguiar, j. em 25-11-2002, grifo nosso).

Do exposto, denota-se que o Superior Tribunal de Justiça buscou nas varas de família qual a prática adotada, e considerouse razoável o requerimento da exoneração de alimentos nos autos da ação originária, pois, conforme Zuliani (2007, p. 70), o contrário geraria um formalismo exagerado, além de que não 
há razoabilidade na exoneração automática dos alimentos, pois ensejaria ao filho o ônus de ingressar com uma ação de alimentos que serviria apenas para manter uma situação já existente.

Afinal, de acordo com o que já foi exaustivamente demonstrado e afirmado, Farias $(2005$, p. 36 - 37) assevera que o fato de o filho ser civilmente capaz não é razão para a cessação dos alimentos, pois, para que a mesma ocorra, deve estar provada a necessidade do alimentando e a impossibilidade do alimentante, uma vez que mesmo ausente o dever de sustento, existe a obrigação de prestar alimentos, decorrente da relação de parentesco e da solidariedade familiar, que não cessa com a maioridade.

Os próprios precedentes da Súmula 358 do Superior Tribunal de Justiça (BRASIL, 2008) demonstram que o entendimento nela evidenciado não é restrito a algumas situações específicas, como pretende Cahali (2006, p. 467 - 468):

$[\ldots]$

5. Lado outro, sem razão a impetração no que tange à exoneração da obrigação de prestar alimentos, ante a maioridade do alimentando.

É cediço que o entendimento desta Corte Superior se filiou à corrente de que cabe as instâncias ordinárias aferir a necessidade, não sendo a maioridade, por si só, critério automático da cessação da obrigação alimentar. Deve o magistrado oportunizar ao alimentando o direito de se manifestar sobre a exoneração.

[...] (STJ, HC n. 77.839, de São Paulo, Rel. Min. Hélio Quaglia Barbosa, j. em 09-10-2007, grifo nosso).

E ainda:

$[\ldots]$

Sobre esse tema, o STJ já proclamou que o advento da maioridade extingue o pátrio poder, mas não revoga, automaticamente, o dever de prestar 
alimentos, que passam ser devidos por efeito da relação de parentesco. A teor dessa orientação, antes de extinguir o encargo de alimentar, deve-se possibilitar ao alimentado demonstrar, nos mesmos autos, que continua a necessitar de alimentos.

[...] (STJ, AgRg. no Ag. n. 655.104, de São Paulo, Rel. Min. Humberto Gomes de Barros, j. em 28-062005, grifo nosso).

As decisões apresentadas, apenas corroboram a obrigatoriedade da análise da necessidade no caso concreto, não fazendo qualquer ligação do fim do pensionamento em decorrência de qualquer limite, mas, ao contrário, afirmam que a idade não é fator determinante à ocorrência ou não do pensionamento, desde que haja necessidade.

Salienta-se que a intenção neste trabalho, não é defender que os filhos, e que qualquer filho, continue recebendo alimentos por toda sua vida em qualquer situação, mas ao contrário, é demonstrar que cada caso deve ser analisado como o único, pois realmente o é, de modo a impossibilitar que aos vinte e quatro anos, ou que ao término da faculdade, os filhos deixem de receber alimentos indistintamente, em qualquer situação.

Essa continuidade dos alimentos para além dos termos jurisdicionais apresentados não deve visar o estímulo do ócio, e de fato, não deve estimulá-lo, o que mais uma vez, se conseguirá por meio da verificação cuidadosa de cada caso.

Enquanto houver necessidade dos filhos e possibilidade dos pais, estes sempre deverão alimentos àqueles, seja em razão do dever de sustento, ou em razão da relação de parentesco. Do mesmo modo que os pais - tenham eles trinta ou noventa anos, ou qualquer outra idade - poderão também pedir alimentos aos seus filhos, desde que presente a necessidade dos pais e a possibilidade dos filhos.

A relação de parentesco sempre existirá entre pais e filhos, a solidariedade familiar não tem qualquer prazo de duração, e a dignidade da pessoa humana sempre deve ser respeitada. 


\section{CONCLUSÃO}

Após a explanação sobre a pensão alimentícia, constatou-se sua grande importância em razão de que se refere à subsistência de um ser humano, atinente ao direito à vida e à vida digna, de acordo com preceito constitucional, de modo que seu conceito abrange não somente o necessário à sobrevivência, podendo se estender a outras necessidades que precisam ser supridas para o respeito à dignidade da pessoa humana.

A importância dos alimentos também foi constatada pelo fato de serem de interesse público, de modo a atrair a utilização do princípio constitucional da solidariedade e a gerar o entendimento de que suas normas são de ordem pública.

A partir da leitura de posicionamentos de magistrados, foi possível a confirmação da existência de decisões judiciais que exoneram os pais de prestar alimentos aos seus filhos com base em critérios construídos pelos próprios magistrados em suas decisões, e utilizados sem a verificação mais aprofundada das peculiaridades de cada caso concreto. Segundo esse posicionamento, basta que um filho tenha vinte a quatro anos de idade, seja civilmente capaz, não esteja estudando, ou estude em apenas um período do dia para que se justifique a exoneração de alimentos.

Foram apresentados autores que corroboram para o entendimento em questão, fundamentado com base na extinção do dever de sustento aos 18 anos, que, em razão de sua prorrogação, ou da sua substituição pela obrigação alimentar, poderia perdurar até os 24 anos do alimentando, o que se permitiria em razão dos princípios da solidariedade e da dignidade da pessoa humana; com base na própria jurisprudência e na doutrina; com base em analogia feita com a legislação sobre o imposto de renda; e em presunções, como a de que com 24 anos os filhos já estarão formados, que uma vez formados em curso técnico ou de nível superior, já terão condições de ingressar no mercado de trabalho, e que se, nesse caso, não ingressarem no mercado de trabalho, estarão os filhos vivendo no ócio. 
Com fulcro na doutrina e na legislação sobre alimentos, notadamente o Código Civil e a Constituição da República Federativa do Brasil, e por meio da contraposição ao entendimento posicionamente supramencionado, constatou-se que este não condiz com as normas atinentes ao assunto.

Perceubeu-se, inclusive, que a exoneração descuidada de alimentos pode gerar injustiças, tendo em vista a realidade do desemprego, da necessidade de cursos após a faculdade como meio de se conquistar um lugar no mercado de trabalho, e outros aspectos que foram apresentados apenas no intuito de exemplificar as diversas situações de devem ser analisadas no caso concreto.

Constatou-se, por fim, que a maioridade civil, o alcance de 24 anos e a conclusão em curso de nível superior, bem como qualquer critério que possa ser utilizado genericamente pelos magistrados em suas decisões, não podem ser razões únicas da exoneração de alimentos, uma vez que, em razão da reciprocidade na prestação dos alimentos, existente na relação de parentesco, que envolve a relação entre pais e filhos civilmente capazes, os alimentos devem continuar sendo prestados enquanto houver a necessidade do alimentando e a possibilidade do alimentante, pressupostos que somente podem ser verificados com a cuidadosa apreciação das peculiaridades de cada caso concreto.

Desse modo, entende-se, em consonância com o disposto na Súmula 358 do Superior Tribunal de Justiça, que independentemente do alcance da maioridade pelo filho, a exoneração de alimentos só poderá ocorrer se houver a ausência dos pressupostos da necessidade e da possibilidade, o que se verificará no contraditório exercido pelo alimentando.

Esse entendimento não poderia ser diferente, uma vez que se deve atender aos princípios constitucionais da solidariedade e da dignidade da pessoa humana, pois a solidariedade não cessa com a maioridade, e a pessoa civilmente capaz continua sendo sujeito de valor, cuja dignidade sempre deverá ser respeitada. 


\begin{abstract}
This paper deals with the jurisdictional criteria used by the court to decide about the removal or maintenance of pension provision by parents to their children when they are able civilly. For that, initially it is presented the assumptions of the obligation to provide maintenance and the right to receive them, found in the doctrine, to enable a wide comprehension of jurisdictional understanding when carrying out the removal in focus, using pre-determined criteria, which can impair the proper verification of the case.

Thus, at the end there will be sufficient subsidies to confront with these criteria, through legislation and doctrinal arguments.

Considering the topic presented, treated by deductive approach, and the issues it involves, this study makes clear that the age of twenty-four years, the completion of university course, the fact that a child is not a full-time student or is not unable for any reason, such as illness, are circumstances which cannot, by themselves, determine the removal of pension provision by parents because there are situations when the necessity of the child and the possibility of the parent to maintain the pension will persist.
\end{abstract}

Keywords: Parents and children. Legal capacity of children. Jurisdictional understandings. exemption of parent's pension.

\title{
REFERÊNCIAS
}

BEBER, Jorge Luis da Costa. A maioridade dos filhos e a exoneração liminar dos alimentos. Ajuris, Porto Alegre, Associação dos Juízes do Rio Grande do Sul, n. 75, ano XXVI, v. 1, p. 163-171, set. 1999.

BRASIL. Constituição (1988). Constituição da República Federativa do Brasil. Presidência da República. Disponível em: <http://www.planalto.gov. br/ccivil_03/Constituicao/Constituiçao.htm>. Acesso em: 17 jul. 2011. 
BRASIL. Lei 1.474, de 26 de novembro 1.951. Modifica a legislação do impôsto sôbre a renda. Presidência da República. Disponível em: <http:// www.planalto.gov.br/ccivil_03/Leis/1950-1969/L1474.htm>. Acesso em: 17 jul. 2011.

BRASIL. Lei n. 8.069, de 13 de julho de 1990. Dispõe sobre o Estatuto da Criança e do Adolescente e dá outras providências. Presidência da República. Disponível em: 〈http://www.planalto.gov.br/ccivil_03/Leis/L8069.htm〉. Acesso em: 17 jul. 2011.

BRASIL. Lei n. 9.250, de 26 de dezembro de 1995. Altera a legislação do imposto de renda das pessoas físicas e dá outras providências. Presidência da República. Disponível em: <http://www.planalto.gov.br/ccivil_03/LEIS/ L9250.htm>. Acesso em: 17 jul. 2011.

BRASIL. Lei n. 10.406, de 10 de janeiro de 2002. Institui o Código Civil. Presidência da República. Disponível em: <http://www.planalto.gov.br/ ccivil_03/LEIS/2002/L10406.htm>. Acesso em: 17 jul. 2011.

BRASIL. Superior Tribunal de Justiça. Agravo Regimental no Agravo de Instrumento n. 655.104. Agravo regimental. Civil. Família. Exoneração de Alimentos. Maioridade. Universitário. Extinção Automática. Impossibilidade [...]. Relator: Min. Humberto Gomes de Barros. São Paulo. Julgamento 28 jun. 2005. Disponível em: <https://ww2.stj.jus.br/ revistaeletronica/Abre_Documento.asp?sSeq $=561020 \&$ sReg $=20050013277$ $4 \&$ sData $=20050822 \&$ formato $=H T M L>$. Acesso em: 17 jul. 201

BRASIL. Superior Tribunal de Justiça. Habeas Corpus n. 77.839. Habeas corpus. Prisão civil. Débito alimentar. Alegação de desemprego, doação de imóvel e tentativa de acordo extrajudicial. Questões inviáveis na via estreita do writ. Ausência de ilegalidade na decisão proferida pelo tribunal de origem. Maioridade do alimentando. Exoneração automática. Inocorrência [...]. Relator: Min. Hélio Quaglia Barbosa. São Paulo. Julgamento 09 out. 2007. Disponível em: < https://ww2.stj.jus.br/revistaeletronica/Abre_ Documento.asp?sSeq=728193\&sReg $=200700427673 \&$ sData $=20080317 \&$ fo rmato=HTML $>$. Acesso em: 17 jul. 2011.

BRASIL. Superior Tribunal de Justiça. Recurso Especial n. 347.010. Alimentos. Filhos. Maioridade. Extinção [...]. Relator: Min. Ruy Rosado de Aguiar. São Paulo. Julgamento: 25 nov. 2002. Disponível em: < https:// ww2.stj.jus.br/revistaeletronica/Abre_Documento.asp?sSeq=385640\&sReg $=200100986263 \& s$ Data $=20030210 \&$ formato $=H T M L>$. Acesso em: 17 jul. 2011. 
BRASIL. Superior Tribunal de Justiça. Súmula n. 358, de 13 de agosto de 2008. O cancelamento de pensão alimentícia de filho que atingiu a maioridade está sujeito à decisão judicial, mediante contraditório, ainda que nos próprios autos. Disponivel em: < http://www.stj.jus.br/SCON/ sumulas $/$ doc.jsp?livre $=\% 40$ docn $\& \& b=S U M U \& p=$ true $\& t=\& l=10 \& i=114$ >. Acesso em: 17 jul. 2011.

CAHALI, Yussef Said. Dos alimentos. 5. ed. rev. atual. e ampl. São Paulo: Editora Revista dos Tribunais, 2006.

CHINELATO, Silmara Juny. Comentários ao Código Civil: parte especial: do direito de família. AZEVEDO, Antônio Junqueira de (Coord.). São Paulo: Saraiva, 2004. $18 \mathrm{v}$.

COlTRO, Antônio Carlos Mathias. Alimentos e Maioridade: a Súmula STJ 358. Revista Brasileira de Direito das Famílias e Sucessões, Porto Alegre, ano X, v. 6, p. 102 - 108, out./nov. 2008.

CONSELHO DA JUSTIÇA FEDERAL - CJF. IV Jornada de Direito Civil. Enunciado 344, de 2006. A obrigação alimentar originada do poder familiar, especialmente para atender às necessidades educacionais, pode não cessar com a maioridade. Disponível em: <http://www.jf.jus.br/cjf/ cej-publ/jornadas-de-direito-civil-enunciados-aprovados/?searchterm=IV jornada>. Acesso em: 17 jul. 2011.

FARIAS, Cristiano Chaves de. A Família da Pós-Modernidade: Em Busca da Dignidade Perdida da Pessoa Humana. Revista Magister de Direito Civil e Processual Civil, Porto Alegre, ano I, v. 2, p. 101 - 114, set./out. 2004.

FARIAS, Cristiano Chaves de. Alimentos decorrentes do parentesco. In: CAHALI, Francisco José (Coord.); PEREIRA, Rodrigo da Cunha (Coord). Alimentos no código civil: Aspectos civil, constitucional, processual e penal. São Paulo: Saraiva, 2005. p. $21 \square 75$.

GARCIA, Edinês Maria Sormani. Direito de Família: princípio da dignidade da pessoa humana. Leme: LED, 2003.

GONÇALVES, Carlos Roberto. Direito Civil Brasileiro: de acordo com o novo código civil brasileiro (Lei n. 10.406, de 10 \1 2002). 2. ed. rev. e atual. São Paulo: Saraiva, 2006. VI v.

LÔBO, Paulo. Princípio da Solidariedade Familiar. Revista Brasileira de Direito das Famílias e Sucessões, Porto Alegre, ano IX, v. 0, p. 144 - 159, out./ nov. 2007. 
MADALENO, Rolf. A execução de alimentos pela via da dignidade humana. In: CAHALI, Francisco José (Coord.); PEREIRA, Rodrigo da Cunha (Coord). Alimentos no código civil: Aspectos civil, constitucional, processual e penal. São Paulo: Saraiva, 2005. p. 233-262.

PARANÁ. Tribunal de Justiça do Paraná. Apelação Civel n. 10791. Apelação cível. Ação de exoneração de pensão alimentícia [...]. A maioridade civil extingue o poder familiar e, por conseguinte, o dever de prestar alimentos. Todavia, se o alimentado estiver freqüentando curso superior, a obrigação alimentar se estende até que ele complete o curso ou dele desista voluntariamente, respeitando a idade limite de 24 (vinte e quatro) anos. Relator: Des. Augusto Lopes Cortes. Santa Izabel do Ivaí. Julgamento 30 jul. 2008. Disponível em: 〈http://www.tjpr.jus.br〉. Acesso em: 17 jul. 2011.

PEREIRA, Caio Mário da Silva. Instituições de Direito Civil: Direito de Família. Atualização de Tânia da Silva Pereira. 16. ed. rev. e atual. Rio de Janeiro: Forense. 2006. V v.

PEREIRA, Rodrigo da Cunha. Princípios fundamentais norteadores para o direito de família. Belo Horizonte: Del Rey, 2006.

PEREIRA, Rodrigo da Cunha. Teoria Geral dos Alimentos. In: CAHALI, Francisco José (Coord.); PEREIRA, Rodrigo da Cunha (Coord). Alimentos no código civil: Aspectos civil, constitucional, processual e penal. São Paulo: Saraiva, 2005. p. $1 \square 20$.

RIO GRANDE DO SUL. Tribunal de Justiça do Rio Grande do Sul. Agravo de Instrumento n. 70026810689. Agravo de instrumento. Ação de exoneração de alimentos. Liminar de redução no quantum. Descabimento. As alegações do alimentante, de que a alimentada não teria mais necessidades, não têm verossimilhança. Os alimentos foram fixados quando ela já era maior da idade e estava encerrando curso superior. A recente colação de grau, por si só, não é prova suficiente de que as necessidades desapareceram [...]. Relator: Des. Rui Portanova. Porto Alegre. Julgamento 08 out. 2008. Disponível em: 〈http://www.tjrs.jus.br>. Acesso em: 17 jul. 2011.

RIO GRANDE DO SUL. Tribunal de Justiça do Rio Grande do Sul. Apelação Civel n. 70027347442. Apelação cível. Ação de exoneração e revisional de alimentos. Alteração do binômio possibilidade/necessidade. Filho maior que cursa ensino superior. Manutenção dos alimentos por prazo certo [...]. Relator: Des. Ricardo Raupp Ruschel. Porto Alegre. Julgamento 03 dez. 2008. Disponível em: 〈http://www.tjrs.jus.br>. Acesso em: 17 jul. 2011. 
RIZZARDO, Arnaldo. Direito de Família: Lei n. 10.406, de 10.01.2002. 3. ed. Rio de Janeiro: Forense, 2005.

RODRIGUES, Silvio. Direito Civil: direito de família. Atualização de Francisco José Cahali. 28. ed. rev. e atual. São Paulo: Saraiva, 2004. 6 v.

SANTA CATARINA. Tribunal de Justiça de Santa Catarina. Agravo de Instrumento n. 2005.032402-2. Direito civil e processual civil - família -execução de alimentos pelo rito do art. 733 do cpc - advento da idade de 24 anos do alimentado - decisum que exonerou ex officio o dever alimentar a partir dos 24 anos e deu prosseguimento à execução pelo rito do art. 732 do cpc - inconformismo - obrigação alimentar - exoneração automática e ex officio - inadmissibilidade [...]. Relator: Des. Monteiro Rocha. Capital. Julgamento 31 jul. 2008. Disponível em: 〈http://www.tj.sc.gov.br〉. Acesso em: 17 jul. 2011.

SANTA CATARINA. Tribunal de Justiça de Santa Catarina. Apelação Civel n. 2006.022.431-6. Apelação cível. Ações de revisão e exoneração de alimentos. Pedido de dispensa da obrigação ante o alimentado ter completado 18 anos. Dispensa não concedida e majoração dos alimentos. Maioridade que não pode ser considerada para extinção automática da obrigação alimentar [...]. Relator: Des. Sérgio Izidoro Heil. Palmitos. Julgamento 28 nov. 2008. Disponivel em: 〈http://www.tj.sc.gov.br〉. Acesso em: 17 jul. 2011.

SANTA CATARINA. Tribunal de Justiça de Santa Catarina. Agravo de Instrumento n. 2006.028072-3. Agravo de instrumento. Ação revisional de pensão alimentícia. Filha maior. Universitária. Pretensa exoneração. Limite da obrigação até 24 anos de idade. Prorrogação excepcional desse prazo [...]. Relator: Des. Rel. Carlos Prudêncio. Blumenau. Julgamento 03 set. 2008. Disponível em: <http://www.tj.sc.gov.br>. Acesso em: 17 jul. 2011.

SANTA CATARINA. Tribunal de Justiça de Santa Catarina. Agravo de Instrumento n. 2007.019526-9. Agravo de instrumento. Execução de prestação alimentícia. Rito do art. 733, do cpc. Inadimplemento incontroverso. Alimentanda que conclui curso superior, com mais de vinte e quatro anos completos e laborando. Postulação de exoneração automática da obrigação alimentar. Possibilidade [...]. Relator: Des. Henry Petry Junior. Joaçaba. Julgamento 14 mar. 2008. Disponível em: <http://www.tj.sc.gov. br>. Acesso em: 17 jul. 2011.

SANTA CATARINA. Tribunal de Justiça de Santa Catarina. Agravo de Instrumento n. 2007.021.193-4. Agravo de instrumento. Ação de exoneração 
de alimentos. Filho maior. Universitário. Limite da obrigação até 24 anos de idade. Prorrogação excepcional desse prazo até a colação de grau em curso superior [...]. Relator: Des. Carlos Prudêncio. Capital. Julgamento 25 jul. 2008. Disponivel em: 〈http://www.tj.sc.gov.br>. Acesso em: 17 jul. 2011.

SANTA CATARINA. Tribunal de Justiça de Santa Catarina. Agravo de Instrumento n. 2008.021551-9. Agravo de instrumento. Ação de alimentos. Provisórios fixados em 2 (dois) salários-mínimos. Pretensão de exoneração ou redução. 1. Filha maior universitária. Necessidade comprovada em cognição sumária. Dever de pensionamento [...]. Relator: Des. Henry Petry Junior. Chapecó. Julgamento 19 dez. 2008. Disponível em: <http://www. tj.sc.gov.br>. Acesso em: 17 jul. 2011.

SANTA CATARINA. Tribunal de Justiça de Santa Catarina. Agravo de Instrumento n. 2008.032607-0. Agravo de instrumento. Alimentos provisionais. Filho maior de idade. Cursante de curso universitário. Ganhos mensais comprovadamente insuficientes. Relação parental. Dever de solidariedade [...]. Relator: Des. Trindade dos Santos. São João Batista. Julgamento 25 nov. 2008. Disponível em: 〈http://www.tj.sc.gov.br〉. Acesso em: 17 jul. 2011.

SANTA CATARINA. Tribunal de Justiça de Santa Catarina. Agravo de Instrumento n. 2008.048797-6. Direito de família. Ação de exoneração de alimentos. Pretendida a concessão de tutela antecipada para a isenção do encargo alimentar pago em favor do filho. Maioridade civil (19 anos). Alimentando que freqüenta curso técnico de contabilidade e não possui vínculo empregatício. Desnecessidade do percebimento da verba alimentar não demonstrada [...]. Relator: Des. Marcus Túlio Sartorato. Videira. Julgamento 03 nov. 2008. Disponível em: 〈http://www.tj.sc.gov.br〉. Acesso em: 17 jul. 2011.

SANTA CATARINA. Tribunal de Justiça de Santa Catarina. Apelação Civel n. 2001.008188-1. Direito de família. Exoneração de alimentos. Filho maior, universitário. Obrigação do pai de pagar o estabelecimento de ensino limite da obrigação até 24 anos para o estudante universitário. Cessação automática do encargo com a superveniência do termo relativo à idade, independentemente de ação exoneratória [...]. Relator: Des. Mazoni Ferreira. Capital. Julgamento 20-08-2001. Disponível em: <http://www. tj.sc.gov.br>. Acesso em: 17 jul. 2011.

SANTA CATARINA. Tribunal de Justiça de Santa Catarina. Apelação Cível n. 2002.003308-1. Direito de família. Exoneração de alimentos. 
Atingimento da maioridade civil do alimentando. Filho cursando universidade. Obrigação do pai de pagar alimentos. Limite da obrigação até a idade de 24 anos para o estudante universitário [...]. Relator: Des. Mazoni Ferreira. Capital. Julgamento 25 abr. 2002. Disponível em: <http://www. tj.sc.gov.br>. Acesso em: 17 jul. 2011.

SANTA CATARINA. Tribunal de Justiça de Santa Catarina. Apelação Civel n. 2004.000896-1. Apelação cível - ação de exoneração de alimentos - maioridade - filha universitária - obrigação do alimentante de pagar os alimentos - limite da obrigação [...]. Relator: Des. Wilson Augusto do Nascimento. Itapiranga. Julgamento 02 abr. 2004. Disponível em: <http:// www.tj.sc.gov.br>. Acesso em: 17 jul. 2011.

SANTA CATARINA. Tribunal de Justiça de Santa Catarina. Apelação Civel n. 2004.001869-0. Processual civil e civil. Família. Alimentos. Acordo fixando a obrigação até que o menor atinja a maioridade. Alteração do código civil, diminuindo a idade. Desnecessidade de ajuizamento de ação exoneratória. Cancelamento da obrigação alimentar. Impossibilidade. Filho cursando universidade particular. Limite da obrigação até 24 anos de idade [...]. Relator: Des. Luiz Carlos Freyesleben. São Bento do Sul. Julgamento 13 mai. 2004. Disponível em: 〈http://www.tj.sc.gov.br〉. Acesso em: 17 jul. 2011.

SANTA CATARINA. Tribunal de Justiça de Santa Catarina. Apelação Civel n. 2005.019482-1. Civil e processual civil. Família. Ação de alimentos. Fixação em cinco salários mínimos. Superveniência de termo extintivo do dever de sustento. Pedido de exoneração dos alimentos formulado pelo pai. Possibilidade. Filho que conta vinte e dois anos e não segue o aperfeiçoamento de seus estudos [...]. Relator: Des. Luiz Carlos Freyesleben. Balneário Camboriú. Julgamento 06 mai. 2008. Disponível em: <http:// www.tj.sc.gov.br>. Acesso em: 17 jul. 2011.

SANTA CATARINA. Tribunal de Justiça de Santa Catarina. Apelação Civel n. 2006.032971-9. Processual civil e civil. Justiça gratuita. Indeferimento. Ausência de prova bastante a autorizar a concessão da benesse. Família. Exoneração de alimentos. Filha cursando universidade particular. Limite da obrigação até 24 anos de idade[...]. Relator: Des. Luiz Carlos Freyesleben. Joaçaba. Julgamento 22 fev. 2007. Disponível em: <http://www.tj.sc.gov. br>. Acesso em: 17 jul. 2011.

SANTA CATARINA. Tribunal de Justiça de Santa Catarina. Apelação Civel n. 2007.036056-7. Apelação cível. Ação de exoneração de prestação alimentar. Valor arbitrado em ação de separação litigiosa (quatro salários 
mínimos mensais). Maioridade civil dos filhos comprovada. Extinção do poder familiar [...]. Relator: Des. Rel. Joel Figueira Júnior. São José. Julgamento 26 mai. 2008. Disponível em: 〈http://www.tj.sc.gov.br〉. Acesso em: 17 jul. 2011.

SANTA CATARINA. Tribunal de Justiça de Santa Catarina. Apelação Cível n. 2008.005655-1. Ação de exoneração de alimentos. Irresignação contra a decisão que extinguiu a obrigação alimentar. Alimentanda que atingiu a maioridade, não freqüenta curso universitário e exerce atividade laborativa. Exoneração que se impunha [...]. Relatora: Desa. Maria do Rocio Luz Santa Ritta. Tijucas. Julgamento 02 out. 2008. Disponível em: <http://www.tj.sc. gov.br>. Acesso em: 17 jul. 2011.

SANTA CATARINA. Tribunal de Justiça de Santa Catarina. Apelação Cível n. 2008.006.428-0. Apelação cível. Ação de exoneração de alimentos. Alimentanda que exerce atividade remunerada, conta com mais de 25 anos de idade e está em fase de conclusão do ensino superior. Entendimento jurisprudencial no sentido de fixar a idade limite de 24 anos de idade [...]. Relator: Des. Sérgio Izidoro Heil. Tubarão. Julgamento 08 jan. 2009. Disponível em: <http://www.tj.sc.gov.br>. Acesso em: 17 jul. 2011.

SANTA CATARINA. Tribunal de Justiça de Santa Catarina. Apelação Cível n. 2008.007203-6. Direito de família. Exoneração de alimentos. Obrigação alimentar assumida em favor da filha através de acordo celebrado em ação de separação judicial. Alimentanda que, apesar da maioridade, possui problemas de saúde e freqüenta curso profissionalizante. Desnecessidade de percebimento dos alimentos não demonstrada [...]. Relator: Des. Marcus Tulio Sartorato. Tubarão. Julgamento 29 set. 2008. Disponível em: <http://www.tj.sc.gov.br>. Acesso em: 17 jul. 2011.

SANTA CATARINA. Tribunal de Justiça de Santa Catarina. Apelação Cível n. 2008.011.146-2. Ação de exoneração de alimentos. Encargo assumido pelo marido em favor da esposa e dos filhos por ocasião da ação de separação judicial. Irresignação contra a decisão que extinguiu a obrigação. Julgamento antecipado da lide. Cerceamento de defesa não ocorrente. alimentos ao filho que atingiu a maioridade e não freqüenta curso. Exoneração que se impunha [...]. Relatora: Desa. Maria do Rocio Luz Santa Ritta. Tubarão. Julgamento 02 out. 2008. Disponível em: <http://www. tj.sc.gov.br>. Acesso em: 17 jul. 2011.

SANTA CATARINA. Tribunal de Justiça de Santa Catarina. Apelação Cível n. 2008.037090-1. Alimentos. Exoneração. Atingimento, pela alimentanda, da maioridade civil. Irrelevância, no caso, postulação rejeitada. Requerida 
que ainda estuda. Ganhos mensais parcos [...]. Relator: Des. Trindade dos Santos. Camboriú. Julgamento 25 nov. 2008. Disponível em: <http://www. tj.sc.gov.br>. Acesso em: 17 jul. 2011.

SANTA CATARINA. Tribunal de Justiça de Santa Catarina. Apelação Cível n. 2008.040304-2. Apelação Cível - Direito De Família - Ação De Exoneração De Alimentos Devidos À Filha - Possibilidade - Maioridade Civil Alcançada Pela Descendente E Conclusão Do Curso De Magistério [...]. Relator: Des. Edson Ubaldo. Araquari. Julgamento 08 jan. 2009. Disponível em: <http://www.tj.sc.gov.br〉. Acesso em: 17 jul. 2011.

VENOSA, Sílvio de Salvo. Direito Civil: direito de família. 7. ed. São Paulo: Atlas, 2007. $6 \mathrm{v}$.

ZULIANI, Ênio Santarelli. Alimentos para filhos maiores. Revista IOB de Direito Civil e Processual Civil, São Paulo, n. 45, ano VIII, v. 3, p. 49-76, jan./ fev. 2007. 